\title{
PENGARUH PEMBERIAN TERAPI MUSIK KLASIK TERHADAP SKALA NYERI PADA IBU POST OPERASI SECTIO CAESAREA DI RSUD Dr. SOEDARSO KOTA PONTIANAK
}

\author{
Winda Ayu Lestari* Hafrizal Riza **Desy Wulandari** \\ *Mahasiswa S1 Keperawatan, **Dosen Keperawatan PSIK \\ Email : windaayulestari@student.untan.ac.id
}

\begin{abstract}
ABSTRAK
Latar Belakang : Sectio caesarea adalah suatu tindakan persalinan melalui pembedahan dengan cara menyayat dinding perut dan dinding rahim untuk melahirkan janin yang pasti menimbulkan nyeri. Salah satu upaya menurunkan nyeri bisa menggunakan terapi musik klasik. Hal ini menjadi ketertarikan peneliti karena terapi musik klasik belum pernah dilakukan atau diberikan kepada ibu post sectio caesarea yang berada di RSUD Dr. Soedarso Kota Pontianak.

Tujuan : Mengidentifikasi pengaruh pemberian terapi musik klasik terhadap skala nyeri pada ibu post sectio caesarea di RSUD Dr. Soedarso Kota Pontianak.

Metode : Penelitian ini adalah penelitian Quasi Eksperimen Design dengan rancangan pre test and post test nonequivalent control group. Sample penelitian adalah ibu post sectio caesarea yang terdiri dari 16 orang pada kelompok intervensi yang diberikan kombinasi analgesik dan terapi musik klasik dan 16 orang pada kelompok kontrol yang hanya diberikan analgesik serta diambil dengan cara Accidental Sampling. Instrumen penelitian adalah lembar pre test dan post test skala Numerik (Numerical Rating Scale atau NRS).

Hasil : Hasil uji Wilcoxon menunjukkan ada penurunan tingkat nyeri yang signifikan sebelum dan sesudah perlakuan pada kelompok intervensi yaitu $\mathrm{p}=0,002(\mathrm{p}<0,005)$ sedangkan pada kelompok kontrol tidak ada penurunan tingkat nyeri yang signifikan sebelum dan sesudah perlakuan yaitu $\mathrm{p}=0,083$, yang berarti ada perbedaan tingkat nyeri pada kelompok kontrol yang tidak diberikan terapi musik klasik dan kelompok intervensi yang diberikan terapi musik klasik.

Kesimpulan :Ada pengaruh pemberian terapi musik klasik terhadap skala nyeri pada ibu post sectio caesarea di RSUD Dr. Soedarso Kota Pontianak.
\end{abstract}

Kata Kunci : Nyeri, Ibu Post Sectio Caesarea, Terapi Musik Klasik

Referensi : (2008-2018) 


\title{
EFFECTIVENESS OF CLASSICAL MUSIC THERAPY ON THE SCALE OF PAIN IN POST SECTIO CAESAREA MOTHERS AT RSUD DR. SOEDARSO PONTIANAK
}

\begin{abstract}
Background: Sectio caesarea is an act of childbirth surgically by cutting the abdominal wall and uterine wall to give birth to a fetus which is sure to cause pain. One effort to reduce pain can use classical music therapy. This is the interest of researchers because classical music therapy has never been done or given to post sectio caesarea mothers who are in Dr. Soedarso Pontianak City. Aims: To identify the effect of classical music therapy on the scale of pain in post-sectio caesarea mothers in RSUD Dr. Soedarso Pontianak.

Methods:This study was quasi experimental with design pretest and post test nonequivalent control group. Sample research was the mother post sectio caesarea consisting of 16 people in groups of intervention and 16 people into control groups, taken by accidental sampling. The research instrument was a sheet of pre test and post test Numerical scale (Numerical Rating Scale or NRS).

Results: Wilcoxon test results showed a significant decrease in pain levels before and after treatment in the intervention group that is $p=0.002(p<0.005)$ whereas in the control group there was no significant decrease in pain levels before and after treatment ie $p=0.083$, which means there is a difference in the level of pain in the control group who were not given classical music therapy and the intervention group who were given classical music therapy.

Conclusion: There is an effect of giving classical music therapy on the scale of pain in post-sectio caesarea mother in RSUD Dr. Soedarso Pontianak.
\end{abstract}

Keywords:pain, post- sectio caesarea mothers, classical music therapy

Reference:(2008-2018) 
PENDAHULUAN

Proses persalinan dapat terjadi melalui dua cara yaitu secara normal dan melalui operasi sectio caesarea. Sectio caesarea merupakan suatu pembedahan yang bertujuan untuk melahirkan anak lewat insisi pada dinding abdomen dan uterus (Oxon \& Forte, 2010). Secara global, fenomena melahirkan dengan operasi sectio caesarea saat ini sedang mengalami peningkatan di berbagai negara berkembang. Seperti tingkat persalinan dengan sectio caesarea di Amerika Serikat, dari 5,5 per 100 kelahiran pada tahun 1970 menjadi 22,7 per 100 kelahiran pada tahun 1985 (Mulyawati dkk, 2011), dan angka kejadian sectio caesarea di Negara Inggris pada tahun 1980 adalah 9\% serta pada tahun 20082009 meningkat menjadi $24,6 \%$ (Afriani, Desmiwarti \& Kandri, 2013), sementara itu di Brazil pada tahun 2004 sebanyak 41,75\% (Sousa et al, 2009). Berdasarkan data survey nasional pada tahun 2007, tingkat persalinan dengan sectio caesarea di Indonesia adalah 921.000 dari 4.039.000 persalinan $(22,8 \%)$.
Berdasarkan hasil studi pendahuluan di Rumah Sakit Umum Daerah Dr. Soedarso pada 17 Maret 2017 didapatkan data jumlah pasien sectio caesarea dari Januari sampai Desember 2016 yaitu 552 orang. Kemudian hasil dari wawancara singkat peneliti pada petugas di RSUD Dr. Soedarso didapatkan bahwa ibu pasca menjalani sectio caesarea mengalami nyeri yang bervariasi dari ringan, sedang, hingga berat dan tidak tertahankan. Studi Pendahuluan yang dilakukan peneliti kepada 20 ibu post sectio caesarea di Rumah Sakit Umum Daerah Dr. Soedarso Kota Pontianak tahun 2017, didapatkan bahwa 5 ibu menyatakan mengalami nyeri berat, 10 ibu mengalami nyeri sedang dan 5 ibu mengalami nyeri ringan. Mereka juga menyatakan bahwa nyeri yang dialami post sectio caesarea mengganggu aktivitas dan mobilisasinya. Rata-rata ibu post sectio caesarea di RSUD Dr. Soedarso mengatakan sudah merasakan nyeri sectio caesarea pada hari pertama post sectio caesarea. 
Adanya fenomena seperti ini, maka peneliti tertarik untuk melakukan penelitian tentang pengaruh pemberian terapi musik klasik terhadap nyeri pada ibu post sectio caesarea di RSUD Dr. Soedarso Kota Pontianak.

\section{METODE}

Penelitian ini menggunakan jenis penelitian kuantitatif dengan desain penelitian quasi eksperiment dengan pendekatan pre test - post test non equivalent with control group.

Penelitian dilakukan selama bulan April sampai Juni dengan mengukur skala nyeri pada ibu post sectio caesarea dengan menggunakan Numerical Rating Scale (NRS) sebelum diberikan terapi musik klasik dan diukur kembali skala nyeri setelah diberikan terapi musik klasik dengan menggunakan instrumen yang sama.

Populasi pada penelitian ini seluruh ibu post sectio caesarea yang mengalami nyeri post sectio caesarea di RSUD Dr. Soedarso sebanyak 552 orang. Sampel pada penelitian ini adalah seluruh ibu post sectio caesarea yang sesuai dengan kriteria inklusi dan eksklusi yang berjumlah 32 orang dengan 16 orang pada kelompok kontrol dan 16 orang pada kelompok intervensi di RSUD Dr. Soedarso Kota Pontianak.

Kriteria inklusi dalam penelitian ini yaitu: responden post sectio caesarea 6 jam post pemberian analgesik, dengan anastesi spinal, yang telah selesai menerima efek anastesi dan sudah menerima terapi analgesik drip intravena diruang rawat inap, dan dengan skala nyeri ringan sampai sedang (1-6). Sedangkan kriteria eksklusi dalam penelitian ini yaitu: responden dengan gangguan pendengaran.

Variabel independen dalam penelitian ini adalah terapi musik klasik, sedangkan Variabel dependen dalam penelitian ini adalah skala nyeri post sectio caesarea yang diukur menggunakan Numerical Rating Scale (NRS).

Tempat pelaksanaan penelitian ini dilakukan di RSUD Dr. Soedarso Kota Pontianak. Penelitian ini dilaksanakan pada bulan April-Juni 2018. 
HASIL

Tabel 1 Karakteristik Responden Berdasarkan Usia, Tingkat Pendidikan dan Pekerjaan

\begin{tabular}{|c|c|c|c|c|c|c|}
\hline \multirow{2}{*}{ Variabel } & \multicolumn{2}{|c|}{ Intervensi } & \multicolumn{2}{|c|}{ Kontrol } & \multicolumn{2}{|c|}{ Total } \\
\hline & $\mathrm{n}$ & $\%$ & $\mathrm{~N}$ & $\%$ & $\mathrm{n}$ & $\%$ \\
\hline \multicolumn{7}{|l|}{ Usia } \\
\hline$<20$ Tahun & 4 & 25,0 & 4 & 25,0 & 8 & 25,0 \\
\hline 20-35 Tahun & 7 & 43,8 & 7 & 43,8 & 14 & 44,0 \\
\hline$>35$ Tahun & 5 & 31,3 & 5 & 31,3 & 10 & 31,0 \\
\hline \multicolumn{7}{|l|}{ Pendidikan } \\
\hline SD & 6 & 37,5 & 6 & 37,5 & 12 & 38,0 \\
\hline SLTP & 1 & 6,3 & 1 & 6,3 & 2 & 6,00 \\
\hline SLTA & 7 & 43,8 & 7 & 43,8 & 14 & 44,0 \\
\hline DIII & 1 & 6,3 & 1 & 6,3 & 2 & 6,00 \\
\hline $\mathrm{S} 1$ & 1 & 6,3 & 1 & 6,3 & 2 & 6,00 \\
\hline \multicolumn{7}{|l|}{ Pekerjaan } \\
\hline IRT & 15 & 93,8 & 15 & 93,8 & 30 & 94,0 \\
\hline SWASTA & 1 & 6,3 & 1 & 6,3 & 2 & 6,00 \\
\hline \multicolumn{3}{|c|}{ Berdasarkan hasil analisis pada } & \multicolumn{4}{|c|}{ paling banyak pada taraf } \\
\hline \multicolumn{3}{|c|}{ tabel 1 dapat disimpulkan bahwa } & \multicolumn{4}{|c|}{ SLTA/SMA $(44,0 \%)$. Dan untuk } \\
\hline jumlah responden & kelon & & \multicolumn{4}{|c|}{ pekerjaan responden kelompok } \\
\hline \multirow{2}{*}{\multicolumn{3}{|c|}{$\begin{array}{l}\text { intervensi dan kelompok kontrol } \\
\text { terbanyak adalah rentang usia } 20 \text { - }\end{array}$}} & \multirow{2}{*}{\multicolumn{4}{|c|}{$\begin{array}{l}\text { intervensi dan kelompok kontrol } \\
\text { yang paling banyak adalah }\end{array}$}} \\
\hline & & & & & & \\
\hline \multicolumn{3}{|c|}{35 tahun $(44,0 \%)$. Tingkat } & \multicolumn{4}{|c|}{ berprofesi sebagai ibu rumah } \\
\hline \multicolumn{3}{|c|}{ pendidikan responden kelompok } & \multicolumn{4}{|c|}{ tangga berjumlah 30 orang } \\
\hline \multicolumn{3}{|c|}{ intervensi dan kelompok kontrol } & \multicolumn{4}{|c|}{$(94,0 \%)$} \\
\hline
\end{tabular}

Tabel 2 Karakteristik Responden Berdasarkan skala nyeri sebelum dan sesudah dilakukan intervensi

\begin{tabular}{lcccc}
\hline Kelompok & $\mathrm{n}$ & \multicolumn{1}{c}{ Sebelum } & \multicolumn{1}{c}{$\begin{array}{l}\text { Mesudah } \\
\text { max })\end{array}$} & $\begin{array}{c}\text { Std. Dev } \\
\text { (Pre - Post) }\end{array}$ \\
& & & $\begin{array}{l}\text { Median (min- } \\
\max )\end{array}$ & \\
\hline Intervensi & 16 & $2,00(1-2)$ & $1,00(1-2)$ & $(0,447-0,479)$ \\
Kontrol & 16 & $5,00(3-6)$ & $4,00(2-6)$ & $\begin{array}{c}(0,885- \\
\end{array}$ \\
& & & & $1,167)$ \\
\hline
\end{tabular}


Berdasarkan hasil analisis pada tabel 2 dapat dilihat skala nyeri responden sebelum intervensi pada kelompok intervensi didapatkan bahwa nilai median skala nyeri adalah 2,00 dengan nilai terendah 1 dan nilai tertinggi 2 , sedangkan pada kelompok kontrol nilai median skala nyeri 5,00 dengan nilai terendah 3 dan nilai tertinggi 6 .
Nilai skala nyeri sesudah intervensi pada kelompok intervensi didapatkan bahwa nilai median skala nyeri adalah 1,00 dengan nilai terendah 1 dan nilai tertinggi 2, sedangkan pada kelompok kontrol nilai median skala nyeri adalah 4,00 dengan nilai terendah 2 dan nilai tertinggi 6 .

Tabel 3 Hasil Uji Wilcoxon perbedaan skala nyeri pada kelompok intervensi dan kelompok kontrol

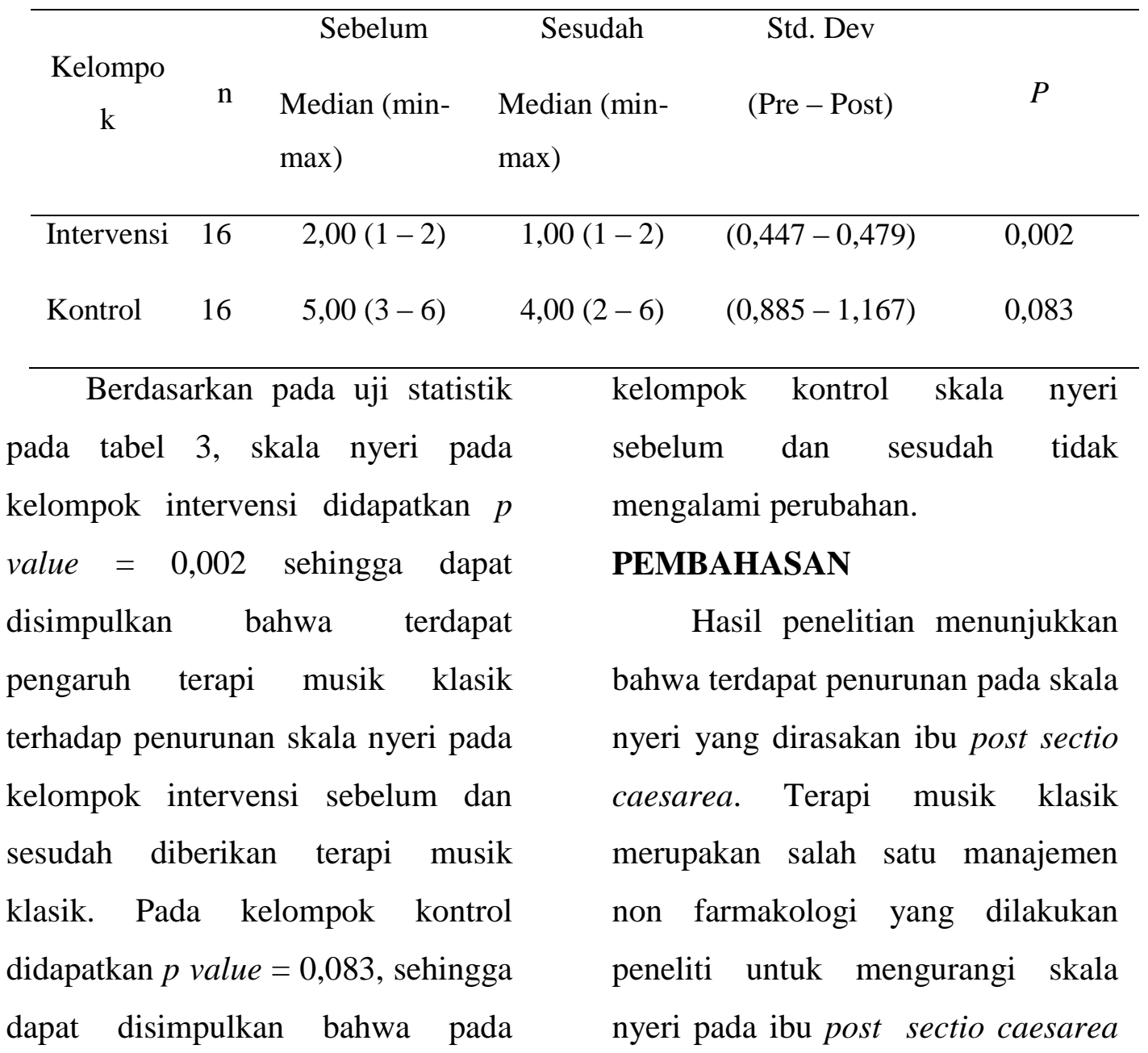


di RSUD Dr. Soedarso Kota Pontianak. Peneliti memiliki pendapat bahwa terapi musik klasik yang dilakukan dapat berpengaruh pada skala nyeri yang ibu rasakan karena hal ini belum pernah dilakukan di RSUD Dr. Soedarso. Sehingga dapat membantu ibu dalam istirahat dan proses pemulihan post sectio caesarea.

Terapi musik klasik ini merangsang kerja saraf rasa sakit dan saraf untuk mendengarkan musik secara bersamaan, sehingga terjadi penurunan hormon Adrenal Corticotropin Hormon (ACTH) yang merupakan hormon stres dan mengeluarkan hormon serotonin yang menimbulkan rasa nikmat dan senang.

Karena, musik itu bekerja pada sistem saraf otonom yaitu bagian sistem saraf yang bertanggung jawab mengontrol tekanan darah, denyut jantung dan fungsi otak, yang mengontrol perasaan dan emosi. Menurut penelitian, kedua sistem tersebut bereaksi sensitif terhadap musik. Saat merasa sakit, kita menjadi takut, frustasi dan marah yang membuat kita menegangkan otot-otot tubuh, hasilnya rasa sakit menjadi semakin parah. Mendengarkan musik secara teratur membantu tubuh rileks secara fisik dan mental, sehingga membantu menyembuhkan dan mencegah rasa sakit. Pada proses persalinan, terapi musik berfungsi mengatasi kecemasan dan mengurangi rasa sakit (Marmi, 2013).

Dengan terdapatnya penurunan skala nyeri pada penelitian ini bahwa terapi musik klasik dapat menurunkan skala nyeri pada ibu post sectio caesarea. Penelitian ini sejalan dengan penelitian Erna (2013), bahwa terdapat pengaruh pemberian terapi musik klasik terhadap penurunan skala nyeri pada ibu post sectio caesarea. Ketika musik klasik diperdengarkan pada ibu post sectio caesarea selama 30 menit, endorphin terbukti akan distimulasi untuk menginhibisi persepsi nyeri.

Hal ini juga sejalan dengan penelitian yang dilakukan Rezki (2014), bahwa terdapat pengaruh terapi musik klasik mozart terhadap intensitas nyeri pasien pascaoperasi seksio sesarea di RSKD Ibu dan 
Anak Siti Fatimah Makassar dengan hasil penelitian yang menunjukkan adanya perbedaan intensitas nyeri yang signifikan sebelum dan sesudah intervensi pada grup eksperimen.

\section{KESIMPULAN}

Berdasarkan hasil penelitian yang dilakukan dapat disimpulkan bahwa terdapat pengaruh pemberian terapi musik klasik terhadap skala nyeri pada ibu post sectio caesarea di Rumah Sakit Umum Daerah Dr. Soedarso Kota Pontianak.

\section{SARAN}

Berdasarkan penelitian dan pembahasan mengenai pengaruh pemberian terapi musik klasik terhadap skala nyeri pada ibu post sectio caesarea di Rumah Sakit Umum Daerah Dr. Soedarso Kota Pontianak, maka peneliti ingin menyampaikan saran berikut: bagi peneliti, diharapkan dapat memanfaatkan hasil penelitian yang telah didapatkan dengan menerapkannya dalam bidang keperawatan terutama dalam hal manajemen nyeri non farmakologis yang tepat untuk mengatasi nyeri pada ibu post sectio caesarea. Untuk peneliti selanjutnya agar dapat mengkaji riwayat persalinan sebelumnya dan mengkaji operasi lain selain sectio caesarea yang mungkin pernah responden lakukan untuk lebih jelas melihat hubungan antara terapi musik klasik dengan tingkat nyeri yang dirasakan.

\section{DAFTAR PUSTAKA}

Afriani, Desmiwarti., \& Kandri. (2013). Kasus Persalinan Dengan Bekas Sectio Caesarea Menurut Keadaan Waktu Masuk dibagian Obstetri dan Ginekologi RSUP Dr. M. Djamil Padang, Vol. 3, No. 2, Hal 116.

Campbell. (2012). Efek Mozart, Memanfaatkan Kekuatan Musik Untuk Mempertajam Pikiran, Meningkatkan Kreativitas, Dan Menyehatkan Tubuh. Jakarta: Gramedia Pustaka Utama.

Fitri, M., Trisyani, M., Maryati, I. (2012). Hubungan Intensitas Nyeri Luka Sectio Caesarea Dengan Kualitas Tidur Pada Pasien Post Partum Hari Ke2 di Ruang Inap RSUD Sumedang. Jurnal Kualitas 
Tidur (diakses 28 September 2015).

Marmi, D. (2013). Intranatal Care Asuhan Kebidanan Pada Persalinan. Pustaka Pelajar: Yogyakarta.

Solehati, \& Rustina. (2013). The Effect of Benson Relaxation on Reduction of Pain Level Among Post Caesarean Section Mother at Cibabat Hospital, Indonesia. GSTF International Journal of Nursing and Health Care (JNHC), 1..

Souse, L. D., Pitangui, A. C., Gomez, F. A., Nakano, A. M., \&Ferreira, C. H. (2009). Measurement and Characteristics of PostCaesarean Section Pain and The Relationship to Limitation of Physical Activities. Acta Paul Enferm, 22, 741-747.

Sumelung, V., Kundre, R., \& Karundeng, M. (2014). Faktor

- Faktor yang Berperan Meningkatnya Angka Kejadian Sectio Caesarea di Rumah Sakit Umum Daerah Lium Kendage Tahuna. Ejournal keperawatan, 2.
Verstraete, M., \& Velde, M. (2012).

Post-Caesarean Section

Analgesia. Acta

Anesthesiologica Belgica, 63, 147-167.

Yuliana, R. (2012). Asuhan Keperawatan Gangguan Rasa Nyaman Nyeri Pada Ny. S Post Sectio Caesarea Dengan Indikasi Plasenta Previa Di Ruang Kenanga RSUD Karanganyar, STIKes Kusuma Husada Surakarta, Surakarta. 